\title{
Four Cases Presenting with Distinct Associations in Oculoauriculovertebral Spectrum
}

\author{
Hatice Mutlu-Albayrak ${ }^{1, *}$, Cahide Bulutb ${ }^{2}$, Aylin Yücelc ${ }^{3}$ and Hüseyin Çaksen ${ }^{1,2}$ \\ ${ }^{1}$ Department of Pediatrics, Division of Pediatric Genetics, Meram Medical Faculty, University of Necmettin Erbakan, Konya, Turkey \\ ${ }^{2}$ Department of Pediatrics, Division of Pediatric Neurology, Meram Medical Faculty, University of Necmettin Erbakan, Konya, Turkey \\ ${ }^{3}$ Department of Pediatrics, Division of Pediatric Gastroenterology, Meram Medical Faculty, University of Necmettin Erbakan, Konya, Turkey
}

\begin{abstract}
Oculoauriculovertebral spectrum (OAVS) is characterized by a wide spectrum of symptoms and physical features that may vary greatly in range and severity from case to case. Oculo-auriculovertebral disorder (OAVD) represents the mildest form of the disorder, while Goldenhar syndrome presents frequently as the most severe form. Hemifacial microsomia appears to be an intermediate form. Here we report four cases with different phenotypic expressions. Case 1 had unilateral anotia with cardiac and urogenital abnormalities. Case 2 was an offspring of a diabetic mother, presenting with unilateral microtia, facial paralysis and sacral agenesis. Case 3 had unilateral anotia plus hemifacial microsomia and facial clefting accompanied to Hirsprung disease. Case 4 was presenting with microtia/preauricular tags plus hemifacial microsomia without accompanying any other system abnormalities. Two had a positive family history, one of them was represented an autosomal dominant (case 1), and the other was autosomal ressesive mode of inheritance (case 4). Based on these cases, we highlighted the heterogeneity of the presentation and genetic etiology of OAVS.
\end{abstract}

\section{Publication History:}

Received: November 15, 2016

Accepted: December 14, 2016

Published: December 16, 2016

\section{Keywords:}

Oculoauriculovertebral spectrum, Hemifacial microsomia, Goldenhar syndrome

\section{Introduction}

Oculo-auriculo-vertebral spectrum is a term suggested by Gorlin to summarize the different phenotypic expressions of a continuum that has been known as hemifacial microsomia, Goldenhar syndrome, or first and second branchial arch anomalies with areported prevalence of up to $1 / 3500$ births [1].

OAVS affects males more frequently than females by an approximate $3: 2$ ratio [2-4]. OAVS is aetiologically and pathogenetically heterogeneous. In most cases OAVS appears to occur randomly, with no apparent cause (sporadic). However, in some cases, family histories suggest autosomal dominant or recessive inheritance. The presence of familial cases, following autosomal dominant [5-8] or autosomal recessive inheritance $[3,4,9]$. As well as several chromosomal aberrations have been reported on previously in patients with OAVS and several candidate genes have been proposed but no one has been confirmed as causative of the phenotype [10-13]. In addition, some authors propose a multifactorial pattern of inheritance [14]. Environmental causes have also been suggested, such as maternal diabetes during pregnancy, gestational or pre-existing vasoactive drugs, smoking and twinning, assisted reproductive technology indicating that a multifactorial aetiology (environmental and genetic) also contributes to some cases of OAVS [15].

Due to the variable expressivity, there is no consensus regarding the minimum diagnostic criteria for OAVS. Tasse et al [8] suggested either isolated microtia or hemifacial microsomia together with mild ear malformations, such as preauricular tags and hillocks, (suggested to be variants of microtia) as minimal diagnostic criteria. BelezaMeireles et al. [16] suggested that the presence of isolated hemifacial microsomia associated with a family history of OAVS should also be considered to be diagnostic.

Here, we report on four unrelated patients who have distinct phenotypic anomalies compatible with OAVS (Table 1).

\section{Case Reports}

\section{Case 1}

A 4-year and 8-month-old boy was admitted to Pediatric Genetics clinic with speech delay and left-sided anotia. He was born at 32th gestational wk, $1650 \mathrm{gr}$, by cesarean/section (preeclampsia). He was the only child of a non-consanguineous family. Her father had bilaterally anotia with congenital hearing loss. He sat without unsupported at 8 th mo and able to walk at the age of $12 \mathrm{mo}$. He started to speak by the age of 2 but was not able to make sentences. He had right-sided inguinal hernia operation at 18th mo. He was followed with patent ductus arteriosus and atriel septal defect up to $3 \mathrm{yr}$ from Pediatric Cardiology clinic. On his examination his weight was $15 \mathrm{~kg}$ (10th centile), height was $104 \mathrm{~cm}$ (25-50th centile) and frontooccipital head measurement was $47 \mathrm{~cm}(-2 \mathrm{SD}>)$. He had severely malformed peanut-shaped auricle with undeveloped external ear canal on the left-side, micrognathia and double urethral orifice (Figure 1). Hearing test, applied to the right ear, was normal. However the test could not apply to left side due to absence of left external ear canal. On his cranial magnetic resonance imaging, abdominal ultrasonografic screening and vertebral roentgenograms, no additional abnormalities were demonstrated. The Ankara Developmental Screening Inventory was applied to the patient and the psychomotor development of the patient was found normal. He was advised to take speech therapy.

"Corresponding Author: Prof. Friedrich Reiterer, Hatice Mutlu Albayrak, Department of Pediatrics, Division of Pediatric Genetics, Faculty of Medicine, Ondokuz Mayıs University; 55280 Samsun, Turkey; Tel.: +903623121919-3754 E-mail: hatice.mutlualbayrak@omu.edu.tr

Citation: Albayrak HM, Bulutb C, Yücelc A, Çaksen H (2016) Four Cases Presenting with Distinct Associations in Oculoauriculovertebral Spectrum. Int J Pediatr Neonat Care 2: 119. doi: https://doi.org/10.15344/2455-2364/2016/119

Copyright: (c) 2016 Albayrak et al. This is an open-access article distributed under the terms of the Creative Commons Attribution License, which permits unrestricted use, distribution, and reproduction in any medium, provided the original author and source are credited. 
Citation: Albayrak HM, Bulutb C, Yücelc A, Çaksen H (2016) Four Cases Presenting with Distinct Associations in Oculoauriculovertebral Spectrum. Int J Pediatr Neonat Care 2: 119. doi: https://doi.org/10.15344/2455-2364/2016/119

Page 2 of 5

\begin{tabular}{|c|c|c|c|c|}
\hline Clinical features & Case 1 & Case 2 & Case 3 & Case 4 \\
\hline Gender & Male & Male & Male & Male \\
\hline Anotia/Microtia & + (left-sided) & $+($ right-sided $)$ & $+($ left-sided $)$ & $+($ left-sided $)$ \\
\hline Preauricular skin tag & - & - & - & + \\
\hline Hemifasiyel microsomia & - & - & + & + \\
\hline Orofacial cleft & - & - & + & - \\
\hline Vertebral anomaly & - & $\begin{array}{l}\text { Caudal regression } \\
\text { syndrome }\end{array}$ & - & - \\
\hline Cardiac anomaly & $\begin{array}{l}\text { Patent ductus arteriosus+ } \\
\text { atrial septal defect }\end{array}$ & - & Ventricular septal defect & - \\
\hline Urogenital abnormalities & $\begin{array}{l}\text { Double urethral orifice, } \\
\text { inguinal hernia }\end{array}$ & - & Cryptorchism & - \\
\hline $\begin{array}{l}\text { Gastrointestinal system } \\
\text { abnormalities }\end{array}$ & - & - & Hirsprung disease & - \\
\hline $\begin{array}{l}\text { Central nervous system } \\
\text { abnormalities }\end{array}$ & - & - & - & - \\
\hline $\begin{array}{l}\text { Delay of motor development/ } \\
\text { intellectual disability }\end{array}$ & - & - & - & - \\
\hline Other abnormalities & - & $\begin{array}{l}\text { Choanal atresia, facial } \\
\text { paralysis }\end{array}$ & & \\
\hline Family history & + & - & - & + \\
\hline
\end{tabular}

Table 1: Clinical features of the cases.

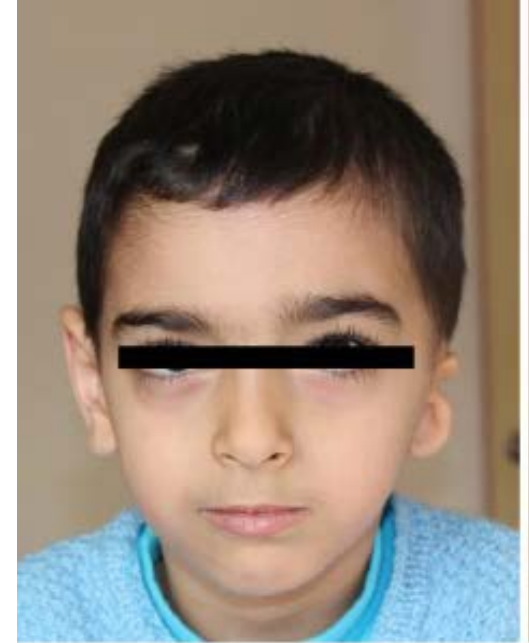

Figure 1: Clinical aspects of the case 1.

\section{Case 2}

A 5-year and 4-month-old boy was referred to Pediatric Genetics clinic because of microtia and caudal regression syndrome. He was born at 38th gestational week, 2710 gr, by cesarean/section. He was the second child of a non-consanguineous family. Her mother was disagnosed as gestational diabetes mellitus and took insulin treatment through the third trimester. He had right-sided choanal atresia repairment on 65th days of his life. One year ago, he admitted to Pediatric Nephrology clinic with enuresis diurna and got diagnosis of caudal regression syndrome. He started to walk and speak at the age of $15 \mathrm{mo}$. On his examination his weight was $15 \mathrm{~kg}$ (3th centile), height was $106 \mathrm{~cm}$ (10th centile) and frontooccipital head measurement was $40 \mathrm{~cm}(-2 \mathrm{SD}>)$. He had right-sided peanut shape auricula with intact external ear canal, peripheric facial palsy and sacral dimple
(Figure 2a, Figure $2 \mathrm{~b}$ and Figure 2C). Vertebral roentgenogram and lumbosacral magnetic resonance imaging showed the agenesis of sacrum and coccyx (Figure 2d and Figure 2e). On his cranial magnetic resonance imaging, abdominal ultrasonografic and echocardiographic screening, no additional abnormalities were demonstrated. Hearing test was applied for both ear and evaluated as normal.

\section{Case 3}

A 2-year and 7-month-old boy was referred to Pediatric Genetics clinic because of unilateral faciel clefting and anotia. He was born as a second child of a non-consanguineous family at 40th gestational wk, $3600 \mathrm{gr}$, by spontaneous vaginal delivery. He failed to pass meconium within $48 \mathrm{hr}$ of delivery and was diagnosed as Hirsprung disease on the postnatal 3rd day (Figure 3). He had cryptorchidism operation at 
Citation: Albayrak HM, Bulutb C, Yücelc A, Çaksen H (2016) Four Cases Presenting with Distinct Associations in Oculoauriculovertebral Spectrum. Int J Pediatr Neonat Care 2: 119. doi: https://doi.org/10.15344/2455-2364/2016/119
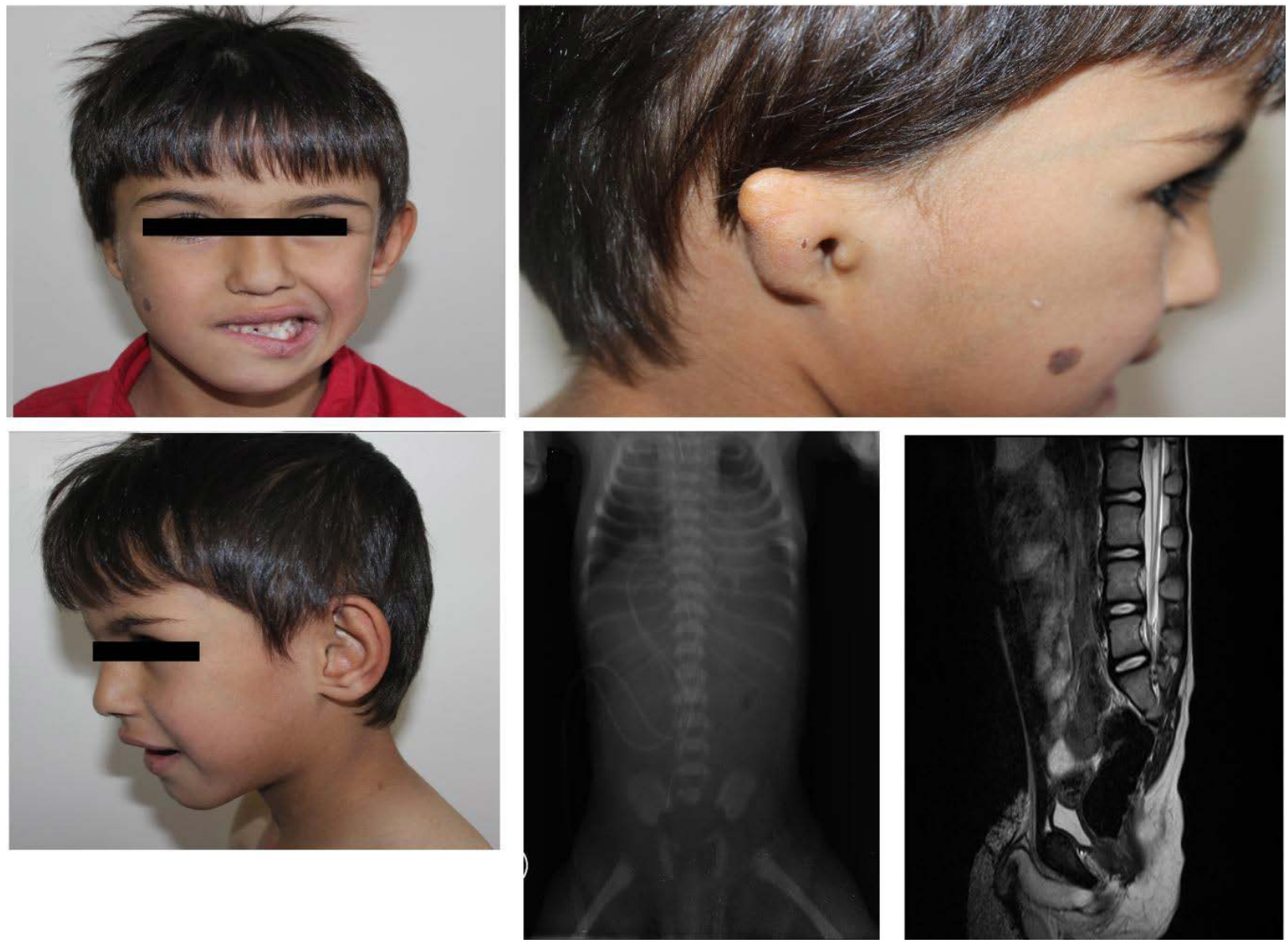

Figure 2: Clinical aspects of the case 2.
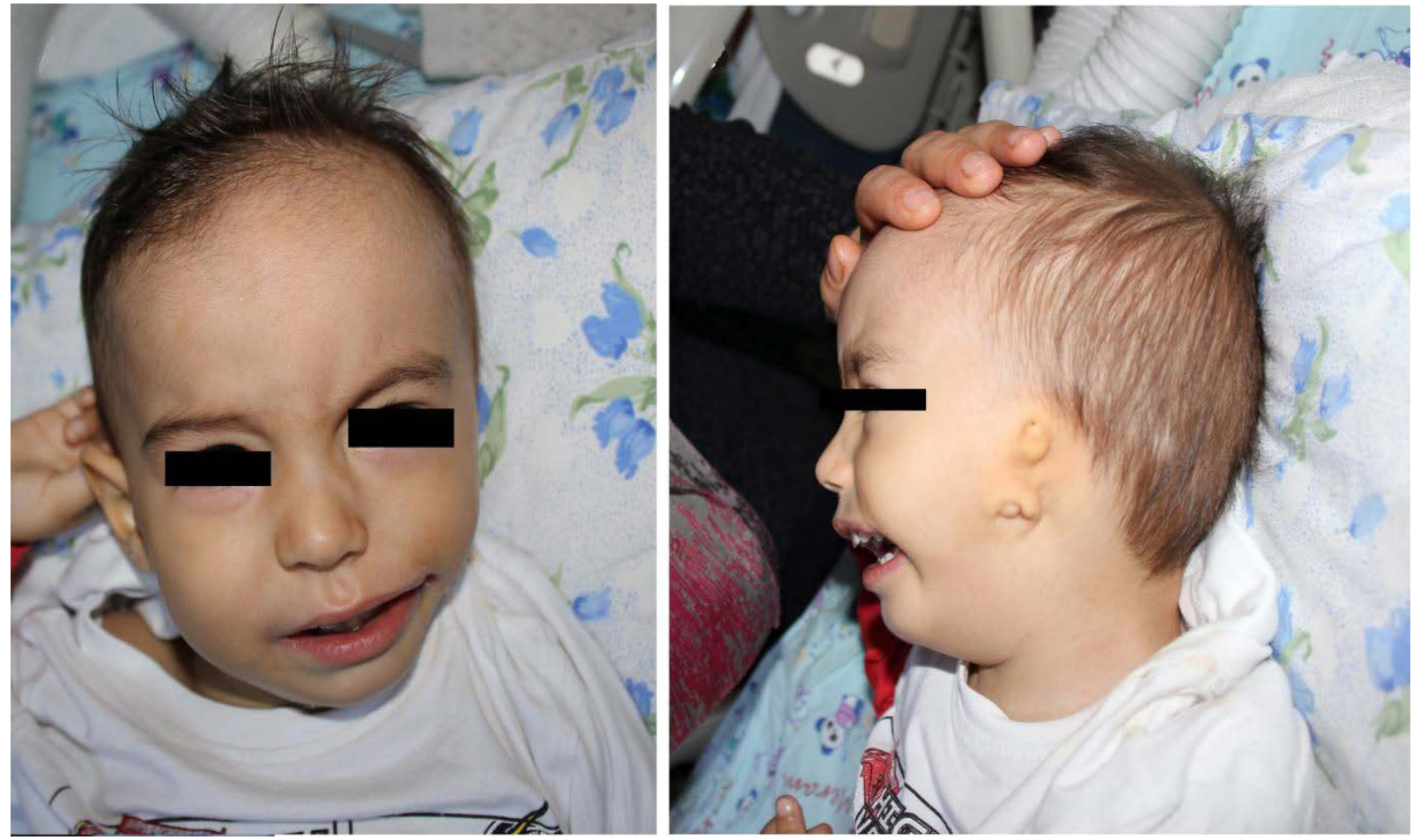

Figure 3: Clinical aspects of the case 3. 
the age of 8 mo and has undergone multiple surgeries with Hirsprung disease up to 2 yr. He sat without unsupported at 8 th mo, able to walk at the age of $12 \mathrm{mo}$ and started to speak by the age of $12 \mathrm{mo}$. On his examination his weight was $13 \mathrm{~kg}$ (25th centile), height was $92 \mathrm{~cm}$ (50th centile) and frontooccipital head measurement was $45 \mathrm{~cm}$ $(-2 \mathrm{SD}>)$. He had left-sided severely malformed auricle with absent external ear canal, Tessier 7 type orofacial clefting and mandibular hypoplasia (Figure 3). Hearing test, applied to the right ear, was normal. Echocardiograhic screening showed muscular ventricular septal defect. However the test could not apply to left side due to absence of left external ear canal. On his cranial magnetic resonance imaging, abdominal ultrasonografic screening and vertebral roentgenograms, no additional abnormalities were demonstrated.

\section{Case 4}

A 5-month-old boy was referred to Pediatric Genetics clinic because of his dysmorphic appearence. He was born as a second child of a non-consanguineous family (his mother and father were from same village) at 39th gestational wk, $2000 \mathrm{gr}$, by cesarean/section. It was learned that his first degree cousin (the son of his uncle) had unilateral facial microsomia. He could hold his head in first month, recognize and smile her mother for $4 \mathrm{mo}$. On his examination his weight was $4000 \mathrm{gr}$ (3th centile $>$ ), height was $60 \mathrm{~cm}$ (3th centile) and frontooccipital head measurement was $38 \mathrm{~cm}$ (3th centile $>$ ). $\mathrm{He}$ had triangular face, downslanding palpebral fissures, arched eyebrows, broad and low nasal root, hypoplasia of the left ala nasi, thin upper lip, down turned mouth, mandibular hypoplasia, left-sided severely malformed auricle with intact external ear canal and bilateral preauricular skin tag (Figure 4). Hearing test, applied to the right and left ears, were normal. On his cranial magnetic resonance imaging, abdominal ultrasonografic screening and vertebral roentgenograms, no additional abnormalities were demonstrated.

\section{Discussion}

OAVS is an extremely complex and heterogeneous condition that affects primarily aural, oral and mandibular development. The disorder is characterized by a wide spectrum of symptoms and physical features that may vary greatly in range and severity from case to case $[1,5]$.

The exact etiology is not known. However, it is possible that abnormal embryonic vascular supply, disrupted mesodermal migration or some other factor leads to defective formation of the branchial and vertebral systems [17].

Most cases of OAVS reported are sporadic but familial cases have been described. A few families were reported to have an autosomal recessive inheritance $[3,4,9]$, other families' presentation of the syndrome strongly supported an autosomal dominant inheritance [58]. Two of our four cases had a positive family history, one of them was represented an autosomal dominant (case 1), and the other was autosomal ressesive mode of inheritance (case 4).

OAVS is usually more common in male [2-4] and the male predominance in four cases was supported the literature.

Hemifacial microsomia is a common birth defect, typically affects the external ear, middle ear, mandible and temporomandibular joint, muscles of mastication and facial muscles, and other facial soft tissues

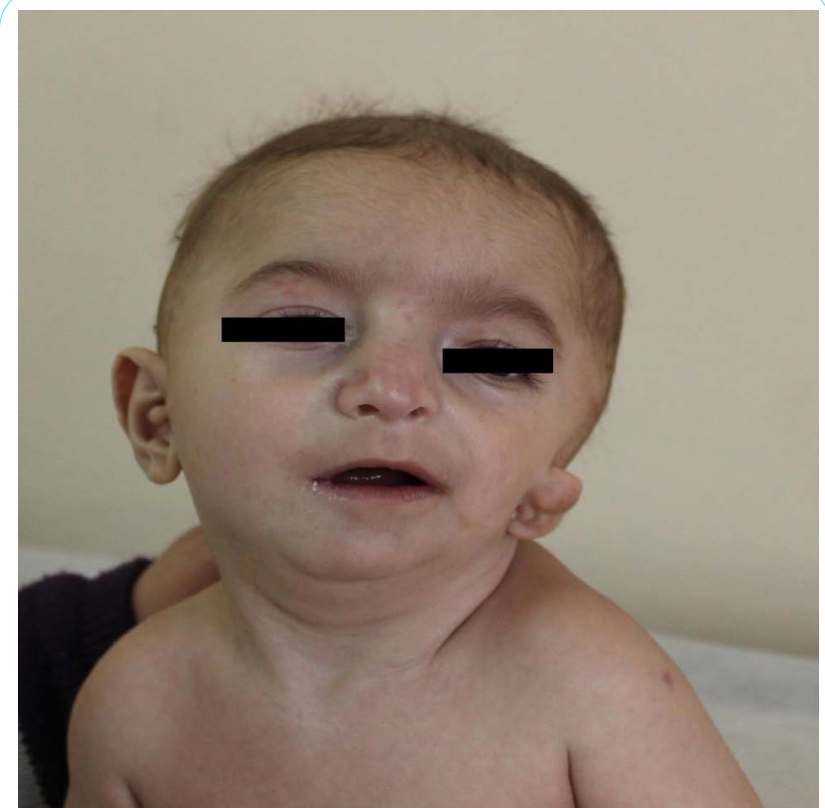

Figure 4: Clinical aspects of the case 4.

on the affected side. Microtia with or without preauricular skin tags may represent the mildest form of the OAVS and has been considered as minimal diagnostic criteria for this condition $[5,8]$. Jin et al. [18] reported $28.4 \%$ of cases with microtia accompanied by hemifacial microsomia and preauriculer tags/sinusus in $\% 14,4$ and eksternal meatus stenosis/atresia in \% 98,6. Hemifacial microsomia was accompanied to microtia in two cases (cases 3 and 4), eksternal meatus stenosus in three cases (cases 1,3 and 4) and only one of them had bilateral preauricular skin tag (case 4).

Facial asymmetry associated with CFM are more likely involve the right side of the face than the left side of the face [19]. However, all of the cases except case 2 had left-sided involvement.

Case 3 had orofacial clefting (Tessier no:7). Though clefts of the orofacial region are among the most common congenital facial defects, the occurrence of lateral facial clefts (Tessier 7 cleft) in conditions such as the OAVS, is very rare $(<5 \%)[20]$.

Malformed and/or fused cervical vertebrae are common, though anomalies can be noted throughout the spine and hemivertebrae are common in OAVS [21]. Maternal diabetes is known to have teratogenic effects. OAVS occurs with a higher incidence in infants of diabetic mothers [22]. Only one in four cases had vertebral anomalies that this case (case 2) was an offspring of a diabetic mother and he had caudal regretion syndrome. He had also additional anomalies such as unilateral coanal atresia and facial paralysis.

Two in four cases had congenital cardiac defect (cases 1 and 3) Cardiovascular anomalies have also been associated with OAV [23]. The frequency of cardiovascular heart defects in OAV ranged from $5 \%$ to $58 \%$ with conotruncal defects and septal defects as the most common among patients, as it was manifested in our patient [24].

Limb, renal and central nervous system anomalies have also been observed in patients with OAVS [25]. Two of them had urogenital abnormalities. Case 1 had right-sided inguinal hernia and double 
Citation: Albayrak HM, Bulutb C, Yücelc A, Çaksen H (2016) Four Cases Presenting with Distinct Associations in Oculoauriculovertebral Spectrum. Int J Pediatr Neonat Care 2: 119. doi: https://doi.org/10.15344/2455-2364/2016/119

Page 5 of 5

urethral orifice. Case 3 had left sided cryptorchidism. None of them had central nervous system abnormalities. None of them had development delay nor intellectual disability. Only case 1 had delay of speech because of having deaf parents.

Only case 3 had gastrointestinal abnormality (Hirsprung disease). Gastrointestinal system abnormalities accompanied to OAVS was very occasionally reported [19], even in according to our knowledge, only one case of OAVS associated with Hirschsprung disease [26] has been reported.

Some patients with OAVS have clinical findings that overlap with other syndromes (i.e. Branchio-oto-renal spectrum disorders, mandibulofacial dysostosis Treacher Collins, Townes-Brocks and CHARGE syndromes) involving structures derived from the first and second pharyngeal arches [19]. Unlike OAVS, individuals with the diagnoses of these type of syndromes typically have symmetric facial malformations. All our cases meet the minimal diagnostic criteria (hemifacial microsomia (asymmetric hypoplasia of facial structures) with preauricular tags or microtia (with or without preauricular skin tags)) and had additional several malformations however none of them had clinical features of the other syndromes as considered in the differential diagnosis.

\section{Conclusion}

Not all patients with OAVS present with all the common features. These reported four cases supports the hypothesis advancing OAVS as a genetically heterogeneous disorder.

\section{Competing Interests}

The authors declare that they have no competing interests.

\section{References}

1. NORD. Available at: https://www.rarediseases.org/rare-diseaseinformation/rare diseases/bylD/346/viewFullReport

2. Shaw GM, Carmichael SL, Kaidarova Z, Harris JA (2004) Epidemiologic characteristics of anotia and microtia in California, 1989-1997. Birth Defects Res A Clin Mol Teratol 70: 472-475.

3. García-Reyes JC, Caro MA, Vega P, Ospina JC, Zarante AM (2009) Zarante I. Epidemiology and risk factors for microtia in Colombia. Acta Otorrinolaringol Esp 60: 115-119.

4. Sánchez O, Méndez JR, Gómez E, Guerra D (1997) Clinico-epidemiologic study of microtia. Invest Clin 38: 203-217.

5. Tasse C, Majewski F, Böhringer S, Fischer S, Lüdecke HJ, et al. (2007) A family with autosomal dominant oculo-auriculo-vertebral spectrum. Clin Dysmorphol 16: 1-7.

6. Vendramini-Pittoli S, Kokitsu-Nakata NM (2009) Oculoauriculovertebra spectrum: report of nine familial cases with evidence of autosomal dominan inheritance and review of the literature. Clin Dysmorphol 18: 67-77.

7. Stoll C, Viville B, Treisser A, Gasser B (1998) A family with dominant oculoauriculovertebral spectrum. Am J Med Genet 78: 345-349.

8. Tasse C, Böhringer S, Fischer S, Lüdecke HJ, Albrecht B, Horn D, et al. (2005) Oculo-auriculo-vertebral spectrum (OAVS): clinical evaluation and severity scoring of 53 patients and proposal for a new classification. Eur $J$ Med Genet 48: 397-411.

9. Werler MM, Sheehan JE, Hayes C, Mitchell AA, Mulliken JB (2004) Vasoactive exposures, vascular events, and hemifacial microsomia. Birth Defects Research (Part A) 70: 389-395.

10. Balcı S, Engiz O (2011) Goldenhar syndrome phenotypes and 22q11 deletion. Am J Med Genet 155A: 458

11. Ballesta-Martínez MJ, López-González V, Dulcet LA, Rodríguez Santiago B, Garcia-Miñaúr S, Guillen-Navarro E. Autosomal dominant oculoauriculovertebral spectrum and 14q23.1 microduplication. Am J Med Genet A 161A: 2030-2035.

Int J Pediatr Neonat Care

ISSN: $2455-2364$
12. Gimelli S, Cuoco C, Ronchetto P, Gimelli G, Tassano E (2013) Interstitial deletion $14 \mathrm{q} 31.1 \mathrm{q} 31.3$ transmitted from a mother to her daughter, both with features of hemifacial microsomia. J Appl Genet 54: 361-365.

13. Brun A, Cailley D, Toutain J, Bouron J, Arveiler B, et al. (2012) $1.5 \mathrm{Mb}$ microdeletion in 15q24 in a patient with mild OAVS phenotype. Eur J Med Genet 55: 135-139

14. Farra C, Yunis K, Yazbeck N, Majdalani M, Charafeddine L, et al. (2011) A Lebanese family with autosomal recessive oculo-auriculo-vertebral (OAV) spectrum and review of the literature: is OAV a genetically heterogeneous disorder? Appl Clin Genet 4: 93-97.

15. Hartsfield JK (2007) Review of the etiologic heterogeneity of the oculoauriculo-vertebral spectrum (Hemifacial Microsomia). Orthod Craniofac Res 10: 121-128.

16. Beleza-Meireles A, Clayton-Smith J, Saraiva JM, Tassabehji M (2014) Oculo-auriculo-vertebral spectrum: a review of the literature and genetic update. J Med Genet 51: 635-645.

17. Kirby ML, Waldo KL. 1990. Role of neural crest in congenital heart disease. Circulation 82: 332-340.

18. Jin L, Hao S, Fu Y, Zhang T, Wang Z (2010) Clinical analysis based on 208 patients with microtia (especially reviewed oculo-auriculo-vertebral spectrum, hearing test, CT scan). Turk J Pediatr 52: 582-587.

19. Heike CL, Hing AV (2015) Craniofacial Microsomia Overview.

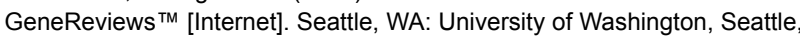
2009.

20. Witters I, Schreurs J, Van Wing J, Wouters W, Fryns JP (2001) Prenata diagnosis of facial clefting as part of the oculo-auriculo-vertebral spectrum. Prenat Diagn 21: 62-64.

21. Stueckle L, Saltzman BS, Luquetti D, Hing AV, Evans KN (2014) Renal and spine screening in sub-phenotypic populations of patients with craniofacial microsomia. American Cleft Palate- Craniofacial Conference, Indianapolis, IN.

22. Wang R, Martínez-Frías ML, Graham JM Jr. (2002) Infants of diabetic mothers are at increased risk for the oculo-auriculo-vertebral sequence: $\mathrm{A}$ case-based and case-control approach. J Pediatr141: 611-617.

23. Rollnick BR, Kaye Cl, Nagatoshi K, Hauck W, Martin AO (1987) Oculoauriculovertebral dysplasia and variants: phenotypic characteristics of 294 patients. Am J Med Genet 26: 361-375.

24. Rosa RF, Dall'agnol L, Zen PR, Pereira VL, Graziadio C, et al. (2010) Oculo-auriculo-vertebral spectrum and cardiac malformations. Rev Assoc Med Bras 56: 62-66.

25. Engiz O, Balci S, Unsal M, Ozer S, Oguz KK, et al. (2007) 31 cases with oculoauriculovertebral dysplasia (Goldenhar syndrome): clinical, neuroradiologic, audiologic and cytogenetic findings. Genet Couns18: 27788.

26. Lankosz-Lauterbach J, Sanak M (1987) Oculoauriculovertebral syndrome (Goldenhar syndrome) associated with Hirschsprung disease. Pediatr Pol 62: $249-252$. 